\title{
Divergent Photocatalytic Reactions of $\alpha$-Ketoesters Under Triplet Sensitization and Photoredox Conditions
}

\author{
Jian Zheng, + Xiao Dong, and Tehshik P. Yoon* \\ Department of Chemistry, University of Wisconsin-Madison, 1101 University Avenue, Madison, Wisconsin 53706 \\ Supporting Information Placeholder
}

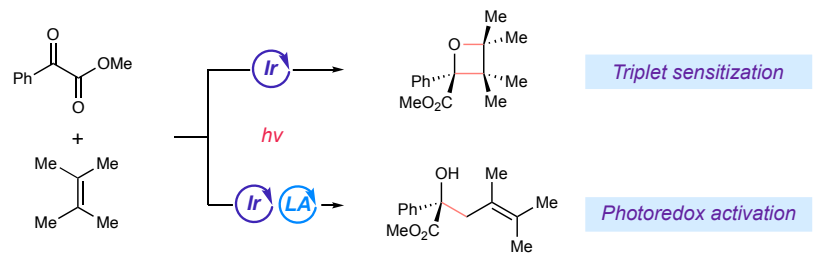

\begin{abstract}
The long-lived triplet excited states of transition metal photocatalysts can activate organic substrates via either energy- or electron-transfer pathways, and the rates of these processes can be influenced by rational tuning of the reaction conditions. The characteristic reactive intermediates that are generated by each of these activation modalities, however, are distinct and can exhibit very different reactivity patterns. Herein, we show that the photocatalytic reactions of benzoylformate esters with alkenes can be directed towards either Paternò-Büchi cycloadditions under conditions that favor energy transfer or allylic functionalization reactions under superficially similar conditions that favor electron transfer. These studies provide a framework for designing other divergent photocatalytic methods that produce different sets of reaction outcomes under photoredox and triplet sensitization conditions.
\end{abstract}

The development of new photocatalytic reactions has recently reemerged as an important theme of research in synthetic chemistry. ${ }^{1}$ The photocatalysts that have most commonly been utilized for these methods to date belong to a family of $\mathrm{Ru}$ and Ir polypyridyl complexes with several features that make them ideal for synthetic applications, including strong absorption in the visible range, excellent chemical stability, and predictable tunability across a wide range of excited-state redox potentials and triplet-state energies. ${ }^{2}$ Most importantly, these complexes undergo efficient intersystem crossing to produce long-lived triplet excited states that can initiate useful organic transformations via either electron-transfer (photoredox) or energy-transfer (triplet sensitization) mechanisms. Though the same photocatalytic triplet excited state is responsible for both pathways, the reactive intermediates that are generated by each are different and exhibit distinctive reactivity patterns. The optimization of photocatalytic reactions, therefore, often requires careful tuning of reaction conditions to ensure that one pathway is favored to the exclusion of the other. ${ }^{3}$ The mechanistic diversity available to photochemical reactions, however, might also offer an opportunity to engineer divergent reactions that give markedly different chemical outcomes under superficially similar conditions. This goal would be valuable because reactions that produce significant structural diversity using a small set of simple reactants can facilitate the discovery of compounds with new chemical and biological properties.

Photoreactions of carbonyl compounds have been an important topic of study throughout the history of organic photochemistry, and the mechanisms of their reactions have been extensively investigated. ${ }^{4}$ Among the oldest and best-known photocycloaddition reactions is the Paternò-Büchi reaction, which classically involves the reaction of excited-state aryl ketones with alkenes to afford structurally complex oxetane products. ${ }^{5}$ As a starting point for our investigations, we examined the photocatalytic reaction of benzoylformate esters. Neckers has explored the photochemistry of these compounds and demonstrated that they are excellent reactants for Paternò-Büchi cycloadditions. ${ }^{6}$ The triplet energies of benzoylformate esters have been reported to be $\sim 62 \mathrm{kcal} / \mathrm{mol}{ }^{7}$ we proposed, therefore, that irradiation of methyl benzoylformate(1) and tetramethylethylene (2) in the presence of a fluorinated Ir(III) complexes with a high triplet-state energy would generate long-lived triplet $\mathbf{1}^{*}$ via Dexter energy transfer (Scheme 1, left). Subsequent $[2+2]$ cycloaddition via the standard stepwise biradical mechanism of the Paternò-Büchi reaction would then afford oxetane 3a. Indeed, upon irradiation of $\mathbf{1}$ and $\mathbf{2}$ in acetonitrile with $465 \mathrm{~nm}$ LEDs in the presence of $1 \mathrm{~mol} \%\left[\operatorname{Ir}\left(\mathrm{dFCF}_{3} \text { ppy }\right)_{2}(\mathrm{dtbbpy})\right] \mathrm{BArF}^{8}{ }^{8}$ Paternò-Büchi cycloadduct (3) was obtained in $74 \%$ yield.

Our laboratory has a long-standing interest in the use of Lewis acid co-catalysts to increase the driving force for photoinduced electron transfer to carbonyl-containing substrates. ${ }^{9}$ We imagined that an appropriate Lewis acid could accelerate electron transfer to ketoester substrate $\mathbf{1}$, outcompeting the rate of energy transfer (Scheme 1, right). The resulting $\operatorname{Ir}(\mathrm{IV})$ complex could then oxidize electron-rich alkene $\mathbf{2}$ to the corresponding radical cation $\left(\mathbf{2}^{\cdot+}\right)$. Deprotonation would afford an allylic radical (5) that could generate product either by combination with the persistent Lewis acid 
Scheme 1. Divergent outcomes of triplet sensitization and photoredox reactions of benzoylformate esters

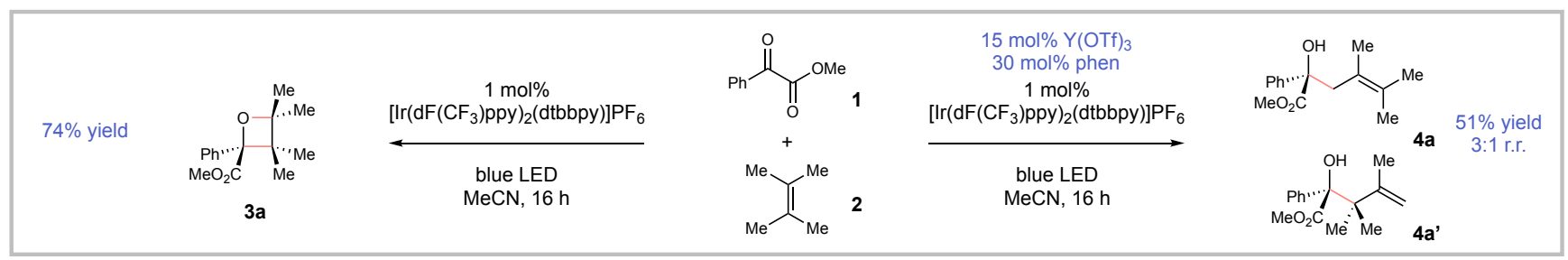

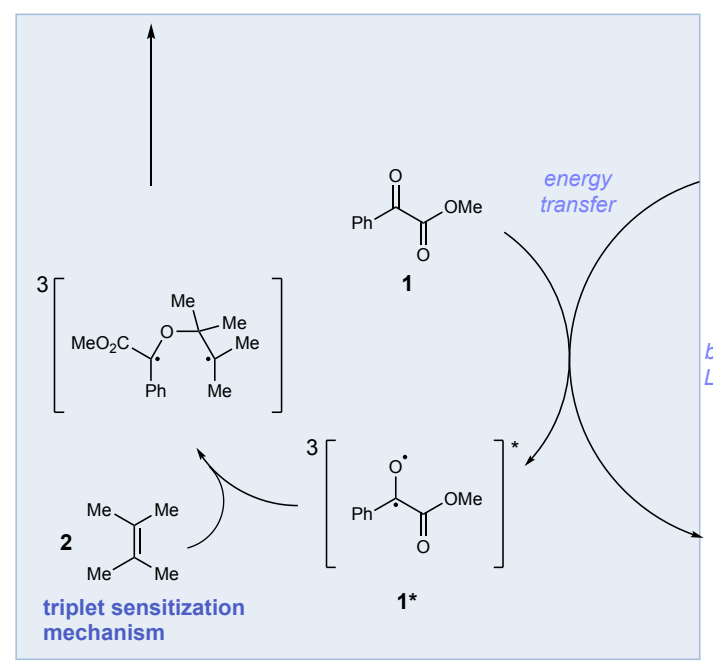

stabilized ketyl radical $\left([\mathrm{Y}]-\mathbf{1}^{\cdot-}\right)^{10}$ or via a Lewis acid catalyzed addition to another equivalent of ketoester. ${ }^{11}$ After a brief screen of Lewis acid co-catalysts, we found that the addition of $15 \mathrm{~mol} \% \mathrm{Y}(\mathrm{OTf})_{3}$ and $20 \mathrm{~mol} \%$ phenanthroline ligand to conditions otherwise identical to those used for the Paternò-Büchi reaction resulted in the formation of $51 \%$ allylic functionalization products as a 3:1 mixture of regioisomers (4a and $\left.\mathbf{4} \mathbf{a}^{\prime}\right)$, in addition to significant amounts of the oxetane cycloadduct.

Table 1. Optimization studies for Paternò-Büchi cycloaddition. ${ }^{a}$

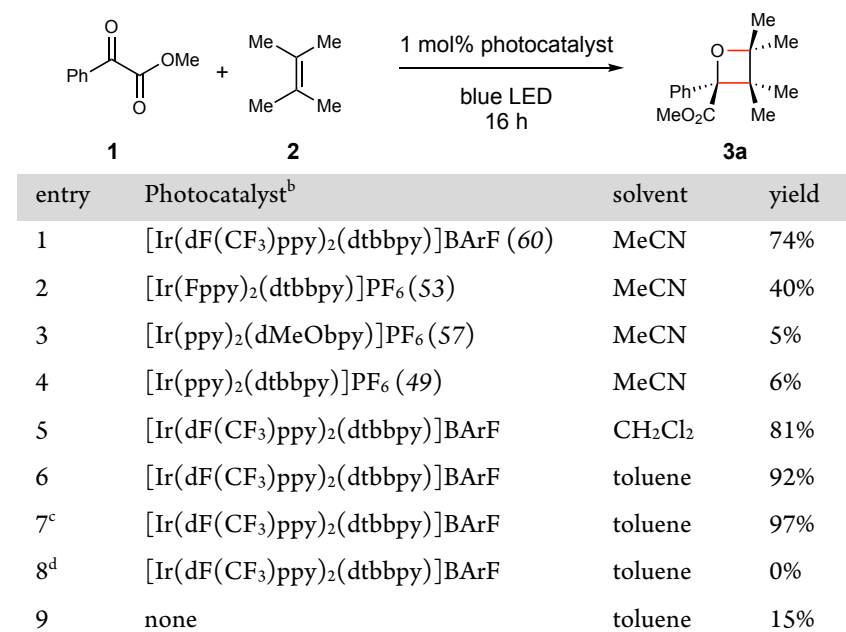

a Reactions conducted using $0.1 \mathrm{mmol} \mathrm{1}, 0.5 \mathrm{mmol} \mathrm{2,} 1 \mathrm{~mol} \%$ $\left[\operatorname{Ir}\left(\mathrm{dFCF}_{3} \text { ppy }\right)_{2}(\mathrm{dtbbpy})\right] \mathrm{BArF}$, and $5 \mathrm{~mL}$ solvent and irradiated with a $16 \mathrm{~W}$ LED lamp $(465 \mathrm{~nm})$ for $16 \mathrm{~h}$ unless otherwise noted. Yields were determined by ${ }^{1} \mathrm{H}$ NMR analysis. ${ }^{b}$ Values in parentheses represent the photocatalyst triplet energies in $\mathrm{kcal} / \mathrm{mol} .{ }^{\mathrm{c}}$ Reaction conducted in $1.5 \mathrm{~mL}$ toluene. ${ }^{\mathrm{d}}$ Reaction conducted in the dark.

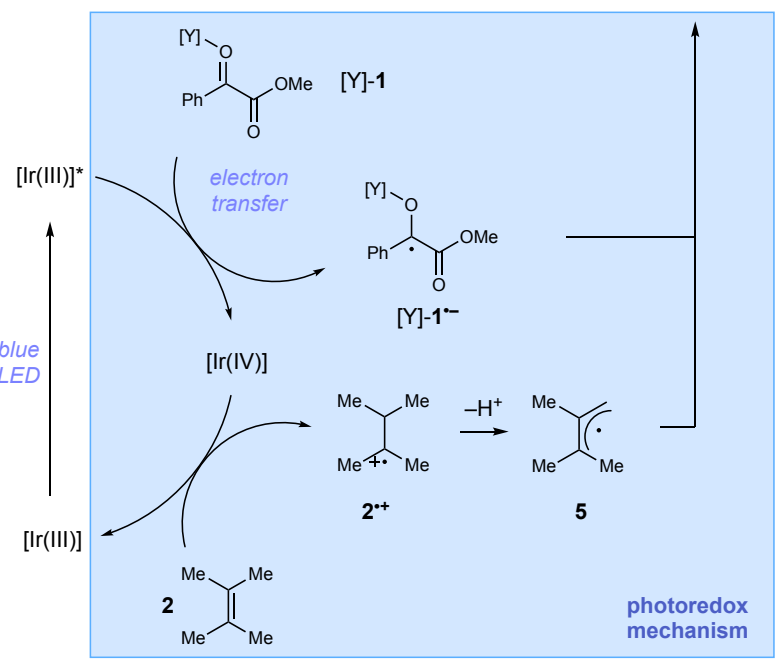

The observation that the partitioning of the reaction between Paternò-Büchi and allylic functionalization pathways could be influenced by reaction conditions was intriguing, and we elected to optimize each of these processes independently. First, Table 1 summarizes the results of studies to improve the yield of the former process. As expected for a triplet sensitization reaction, the yield of PaternòBüchi product is highest using high triplet energy photocatalysts (entries 1-4). Also consistent with a triplet mechanism is the relative insensitivity of the reaction towards the polarity of the solvent (entries 5-7), with the highest yields observed in toluene. The yield is increased at higher concentrations (entry 7). Control experiments show that no product is observed in the absence of light (entry 8); however, a slow Paternò-Büchi reaction was observed in the absence of photocatalyst, which results from a tailing of the absorption of $\mathbf{1}$ into the visible region (entry 9). Nevertheless, product formation in this reaction is dominated by the photosensitized reaction pathway.

Table 2 summarizes an investigation of the scope of this photosensitized Paternò-Büchi cycloaddition. We first examined the scope with respect to the ketoester reaction component. Ester moieties bearing potentially reactive functional groups including alkenes (3d), alkynes (3e), halides (3f), and azides (3g) are well-tolerated. The identity of the arene substituent could also be easily modified with various electron-donating and -withdrawing substituents $(\mathbf{3 h}-$ 3o), although ortho substituents retard the reaction somewhat (3p). Heteroaryl groups are also tolerated ( $\mathbf{3 q}$ and $\mathbf{3 r}$ ). The scope with respect to the alkene was also examined. The reaction was fastest with relatively electron-rich alkenes, consistent with the oxyl radical character of the $n \pi^{*}$ triplet ketone intermediate, although disubstituted aliphatic alkenes afforded reasonable yields of the oxetane cycloadduct (3s and 3t). In all cases, the regioselectivity of the reaction could be predicted by considering the stability of the intermediate 1,4-diradical expected from the conventional stepwise mechanism of the Paternò-Büchi cycloaddition $(\mathbf{3} \mathbf{u}-\mathbf{3 x})$. 
Table 2. Paternò-Büchi scope studies ${ }^{\mathrm{a}}$

$$
\begin{array}{ll}
\mathrm{Me} & \text { 3a, } \mathrm{R}=\mathrm{Me}, 96 \% \text { yield } \\
\cdots \mathrm{Me} & \mathbf{3 b}, \mathrm{R}=\mathrm{Et}, 98 \% \text { yield } \\
\mathrm{RO}_{2} \mathrm{C} & (1.26 \mathrm{~g} \mathrm{scale}, 96 \% \text { yield })^{\mathrm{b}}
\end{array}
$$

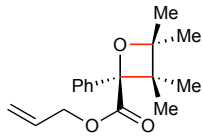

3d, $85 \%$ yield

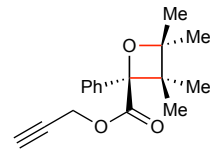

3 e, $84 \%$ yield

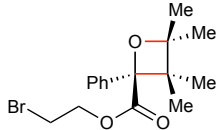

3f, $69 \%$ yield $^{c}$

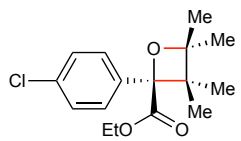

$3 \mathbf{k}, 78 \%$ yield

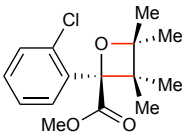

3 p, $59 \%$ yield

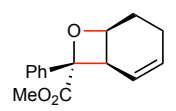

$3 u, 66 \%$ yield

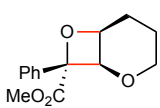

$3 v, 56 \%$ yield

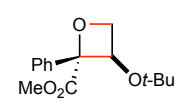

$3 w, 85 \%$ yield

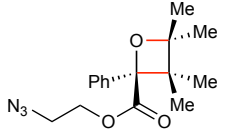

3 g, $51 \%$ yield

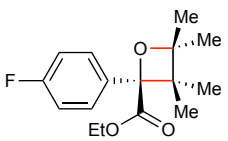

3I, $87 \%$ yield

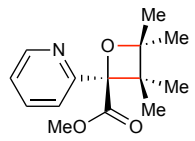

$3 q, 44 \%$ yield

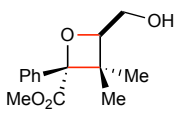

$3 \mathbf{x}, 58 \%$ yield

${ }^{a}$ Reactions conducted using $0.5 \mathrm{mmol} 1,2.5 \mathrm{mmol} 2,1 \mathrm{~mol} \%\left[\operatorname{Ir}\left(\mathrm{dFCF}_{3} \mathrm{ppy}\right)_{2}(\mathrm{dtbbpy})\right] \mathrm{BArF}$, and $7.5 \mathrm{~mL}$ toluene and irradiated with a $16 \mathrm{~W} \mathrm{LED}$ lamp $(465 \mathrm{~nm})$ for $16 \mathrm{~h}$ unless otherwise noted. ${ }^{\mathrm{b}}$ Reaction conducted using $0.5 \mathrm{~mol} \%$ [ $\left.\operatorname{Ir}\left(\mathrm{dFCF}_{3} \text { ppy }\right)_{2}(\mathrm{dtbbpy})\right] \mathrm{BArF} .{ }^{\mathrm{c}}$ Reaction conducted for $24 \mathrm{~h}$.

As a further validation of the triplet mechanism of this photoreaction, we wondered if other fundamental photoreactions of $n \pi^{*}$ triplet ketones could be accessed using the conditions optimized for the Paternò-Büchi cycloaddition. We targeted the Norrish-Yang photocyclization $^{12}$ of ortho-methyl benzoylformates ${ }^{13}$ to access benzofused cyclobutanes that are important structural elements of bioactive drugs and natural products. ${ }^{14}$ Indeed, a variety of ortho-methyl benzoylformates undergo smooth transformation to the benzocyclobutenol products $\mathbf{6 a}-\mathbf{6 h}$ (Table 3 ).

Table 3. Norrish type II reactions under energy-transfer conditions. ${ }^{a}$

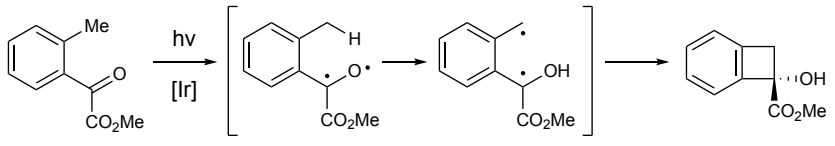

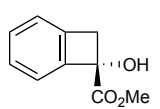

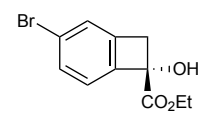

6b, $97 \%$ yield

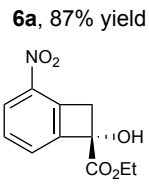

$6 e, 52 \%$ yield
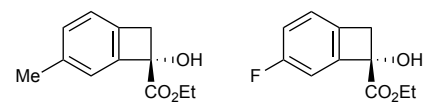

6f, $87 \%$ yield

$6 \mathrm{~g}, 80 \%$ yield

a Reactions conducted using $0.5 \mathrm{mmol}$ ketoester, 1 mol\% $\left[\operatorname{Ir}\left(\mathrm{dFCF}_{3} \text { ppy }\right)_{2}(\mathrm{dtbbpy})\right] \mathrm{BArF}$, and $7.5 \mathrm{~mL}$ toluene and irradiated using a $16 \mathrm{~W}$ LED lamp $(465 \mathrm{~nm})$ for $16 \mathrm{~h}$.

We next undertook studies to optimize the photoredox allylic functionalization process (Table 4). We speculated that the product distribution might be diverted completely towards allylic functionalization by appropriately tuning the identity of the photocatalyst and Lewis acid co-catalyst to maximize the rate of photoredox activation and minimize the rate of energy transfer. First, a screen of alternate ligands for $\mathrm{Y}(\mathrm{OTf})_{3}$ revealed that a slightly more electron-deficient 5-chlorophenanthroline ligand afforded somewhat improved yields of the allylic functionalization product (entries 1-3). We next examined photocatalysts with lower triplet energy and more negative excited state reduction potentials that might further improve the yield of this reaction (entries 4-7). Indeed, $\left[\operatorname{Ir}(\mathrm{ppy})_{2}(\mathrm{dMeObpy}) \mathrm{PF}_{6}\right.$ gave exclusively the allylic functionalization product in $89 \%$ yield (entry 7). Control experiments indicated that the photocatalyst, Lewis acid co-catalyst, and light were all required for the formation of the allylic functionalization product (entries 8-10).

Table 4. Optimization studies for allylic functionalization

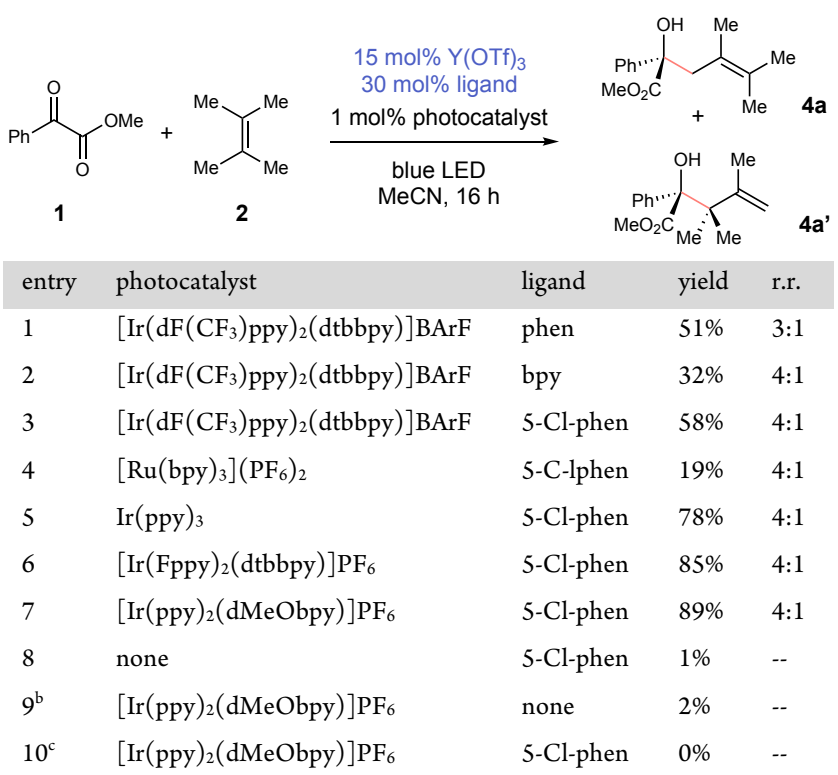

${ }^{\text {a }}$ Reactions conducted using $0.1 \mathrm{mmol} \mathbf{1}, 0.5 \mathrm{mmol} 2,1 \mathrm{~mol} \%$ photocatalyst, $15 \mathrm{~mol} \% \mathrm{Y}(\mathrm{OTf})_{3}, 30 \mathrm{~mol}$ ligand, and $1.5 \mathrm{~mL} \mathrm{MeCN}$ and irradiated with a $16 \mathrm{WLED}$ lamp $(465 \mathrm{~nm})$ for $16 \mathrm{~h}$ unless otherwise noted. Yields were determined by ${ }^{1} \mathrm{H}$ NMR analysis. ${ }^{b}$ Reaction conducted without $\mathrm{Y}(\mathrm{OTf})_{3 .}{ }^{\mathrm{c}}$ Reaction conducted in the dark. 
Table 5. Allylic functionalization scope studies. ${ }^{a}$

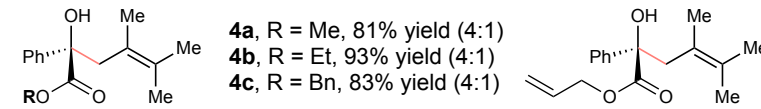

4d, $93 \%$ yield $(5: 1)$

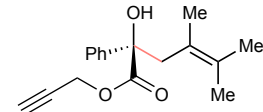

$4 e, 83 \%$ yield $(4: 1)$

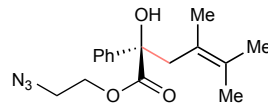

4f, $69 \%$ yield $(4: 1)$

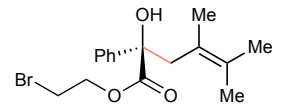

$4 \mathrm{~g}, 87 \%$ yield $(4: 1)^{\mathrm{d}}$

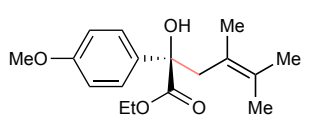

4h, $84 \%$ yield $(4: 1)^{\mathrm{c}}$

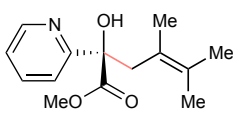

$4 \mathrm{~m}, 51 \%$ yield $(4: 1)$

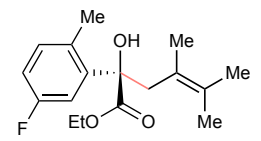

$4 \mathbf{r}, 76 \%$ yield $(9: 1)$

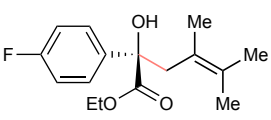

4i, $94 \%$ yield $(4: 1)$

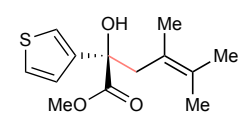

$4 n, 86 \%$ yield $(4: 1)$

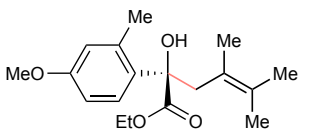

4s, $79 \%$ yield $(>20: 1)^{c}$

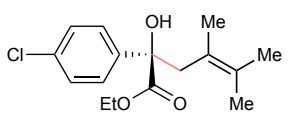

$\mathbf{4 j}, 95 \%$ yield $(4: 1)$

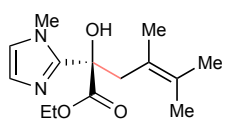

4o, $49 \%$ yield $(4: 1)$

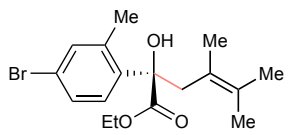

4t, $85 \%$ yield (13:1)

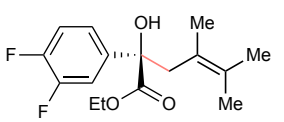

$4 \mathbf{k}, 85 \%$ yield $(4: 1)^{\mathrm{b}}$

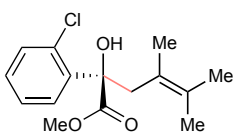

$4 p, 93 \%$ yield $(10: 1)^{d}$

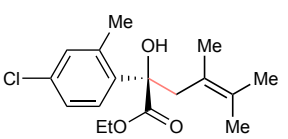

$4 u, 96 \%$ yield $(10: 1)^{c}$

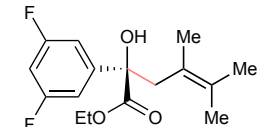

4I, $86 \%$ yield $(4: 1)^{b}$

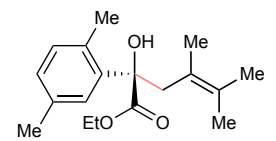

$\mathbf{4 q}, 87 \%$ yield $(14: 1)^{c}$

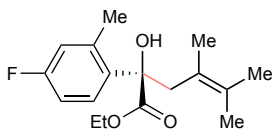

$4 \mathbf{v}, 85 \%$ yield $(14: 1)$

${ }^{\text {a }}$ Reactions conducted using $0.5 \mathrm{mmol} \mathbf{1}, 2.5 \mathrm{mmol} 2,1 \mathrm{~mol} \%$ [ $\left.\operatorname{Ir}(\mathrm{ppy})_{2}(\mathrm{dMeObpy})\right] \mathrm{PF}_{6}, 15 \mathrm{~mol} \% \mathrm{Y}(\mathrm{OTf})_{3}, 30 \mathrm{~mol} \% 5-\mathrm{Cl}-\mathrm{phen}$, and $7.5 \mathrm{~mL}$ toluene and irradiated with a $16 \mathrm{~W}$ LED lamp $(465 \mathrm{~nm})$ for $16 \mathrm{~h}$ unless otherwise noted. Values in parentheses represent the ratio of regioisomers.

${ }^{\mathrm{b}}$ Reaction conducted using $1 \mathrm{~mol} \%\left[\operatorname{Ir}(\mathrm{Fppy})_{2}(\mathrm{dtbbpy})\right] \mathrm{PF}_{6} .{ }^{\mathrm{c}}$ Reaction conducted for $24 \mathrm{~h} .{ }^{\mathrm{d}}$ Reaction conducted for $32 \mathrm{~h}$.

Scope studies exploring the generality of this allylic functionalization are summarized in Table 5. All of the benzoylformates examined in the Paternò-Büchi reaction performed well in this transformation but afforded the allylic functionalization product to the exclusion of the previously observed oxetanes $(\mathbf{4 a}-\mathbf{4 p})$. In general, we obtained relatively modest regioselectivity for the formation of the tetrasubstituted olefin product over the 1,1-disubstituted alkene isomer. However, those benzoylformates bearing bulky ortho substituents gave better selectivities $(\mathbf{4 p - 4 v})$. Importantly, in these cases, we observed no trace of the Norrish-Yang cyclization products.

Scheme 2. Support for a photoredox mechanism.
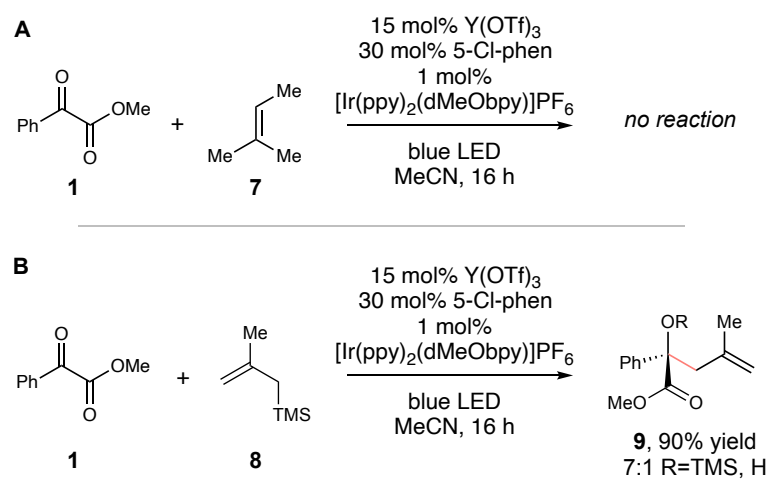

Several lines of evidence support the contention that the allylic functionalization reaction involves a photoredox process. First, cyclic voltammetry performed with benzoylformate $\mathbf{1}$ showed a quasireversible reduction wave at $-1.28 \mathrm{~V}$ vs SCE. The addition of $\mathrm{Y}(\mathrm{OTf})_{3}$ and phen results in a positive shift to $-0.70 \mathrm{~V}$ vs. SCE, which is easily within the range accessible by the excited states of both $\left[\operatorname{Ir}^{*}\left(\mathrm{dFCF}_{3} \text { ppy }\right)_{2}(\mathrm{dtbbpy})\right]^{+}(-0.89 \mathrm{~V} \text { vs SCE })^{8}$ and the more strongly reducing $\left[\mathrm{Ir}^{*}(\mathrm{ppy})_{2}(\mathrm{dMeObpy})\right]^{+}(-1.26 \mathrm{~V}$ vs SCE $)$. Second, this mechanism predicts that the oxidation of tetramethylethylene $\left(+1.45 \mathrm{~V}\right.$ vs SCE) by the oxidized $\left[\operatorname{Ir}(\text { ppy })_{2}(\mathrm{dMeObpy})\right]^{2+}$ catalyst $(+1.21 \mathrm{~V}$ vs SCE) would be slightly endergonic by 5.5 $\mathrm{kcal} / \mathrm{mol}$. Consistent with this expectation, less-electron-rich trisubsitutted alkenes such as $7(+1.98 \mathrm{~V} \text { vs SCE })^{15}$ fail to give any $\mathrm{C}-\mathrm{H}$ functionalization products (Scheme $2 \mathrm{~A}$ ). On the other hand, electron-rich methallylsilane $8(+1.24 \mathrm{~V}$ vs SCE $){ }^{16}$ participates readily in this reaction to afford Sakurai addition product 9 in $90 \%$ yield (Scheme 2B).

In summary, we have shown that divergent reactivity is accessible in the photocatalytic reaction of benzoylformates with alkenes. Under conditions that favor energy transfer, the triplet-state benzoylformate undergoes smooth Paternò-Büchi cycloaddition to afford complex oxetane scaffolds. Under photoredox conditions, on the other hand, the same starting materials undergo selective transformation to allylic functionalization products. These results offer a valuable demonstration that the ability to rationally design systems that favor either photoredox or energy transfer mechanisms offers a means not only to impact the rate of useful photocatalytic transformations but also to rationally alter their chemical outcomes as well.

\section{ASSOCIATED CONTENT}

\section{Supporting Information}

The Supporting Information is available free of charge on the ACS Publications website.

Detailed experimental procedures, full spectroscopic data for all new copounds (PDF).

\section{AUTHOR INFORMATION}

\section{Corresponding Author}

* Tehshik P. Yoon - Department of Chemistry, University of WisconsinMadison, Madison, Wisconsin, 53706, United States. Email: tyoon@chem.wisc.edu

\section{Present Addresses}

†Jian Zheng - Department of Chemistry, Zhejiang University, Hangzhou 310027, Zhejiang, People's Republic of China. 


\section{ACKNOWLEDGMENT}

We dedicate this paper to Prof. Ilhyong Ryu on the occasion of his $70^{\text {th }}$ birthday. We are grateful to Katie Rykaczewski and Prof. Corinna Schindler for sharing unpublished data. Funding for this project was provided by the NIH (GM095666). NMR and MS facilities at UW-

${ }^{1}$ For reviews, see: a) Narayanam, J. M. R.; Stephenson, C. R. J. "Visible Light Photoredox Catalysis: Applications in Organic Synthesis," Chem. Soc. Rev. 2011, 40, 102-113. b) Prier, C. K.; Rankic, D. A.; MacMillan, D. W. C. "Visible Light Photoredox Catalysis with Transition Metal Complexes: Applications in Organic Synthesis,"Chem. Rev. 2013, 113, 5322-5363. c) Twilton, J.; Le, C.; Zhang, P.; Shaw, M. H.; Evans, R. W.; MacMillan, D. W. C. "The Merger of Transition Metal and Photocatalysis," Nature Rev. Chem. 2017, 1, 0052 .

2 a) Juris, A.; Balzani, V.; Barigelletti, F.; Campagna, S.; Belser, P.; von Zelewsky, A. "Ru(II) Polypyridine Complexes: Photophysics, Photochemistry, Electrochemistry, and Chemiluminescence," Coord. Chem. Rev. 1988, 84, 85-277. b) Huckaba, A. J.; Nazeeruddin, M. K. "Strategies for Tuning Emission Energy in Phosphorescent Ir(III) Complexes." Comments Inorg. Chem. 2017, 37, 117-145.

3 a) Lin, S.; Ischay, M. A.; Fry, C. G.; Yoon, T. P. "Radical Cation DielsAlder Cycloadditions by Visible Light Photocatalysis." J. Am. Chem. Soc. 2011, 133, 19350-19353. b) Ischay, M. A.; Ament, M. S.; Yoon, T. P. "Crossed Intermolecular [2 + 2] Cycloaddition of Styrenes by Visible Light Photocatalysis." Chem. Sci. 2012, 3, 2807-2811. c) Nguyen, J. D.; D'Amato, E. M.; Narayanam, J. M. R.; Stephenson, C. R. J. "Engaging Unactivated Alkyl, Alkenyl and Aryl Iodides in Visible-Light-Mediated Free Radical Reactions." Nat. Chem. 2012, 4, 854-859. d) Daub, M. E.; Jung, H.; Lee, B. J.; Won, J.; Baik, M.-H.; Yoon, T. P. "Enantioselective [2+2] Cycloadditions of Cinnamate Esters: Generalizing Lewis Acid Catalysis of Triplet Energy Transfer." J. Am. Chem. Soc. 2019, 141, 9543-9547.

${ }^{4}$ a) B. Dinda, "Photochemistry of Carbonyl Compounds." In Essentials of Pericycli cand Photochemical Reactions, vol. 93, Springer, Switzerland, 2017, pp. 241-275. b)Dantas, J. A.; Correia, J. T. M.; Paixão, M. W.; Corrêa, A. G. Photochemistry of Carbonyl Compounds: Application in Metal-Free Reactions. ChemPhotoChem 2019, 3, 506-520.

${ }^{5}$ For reviews, see: a) Fréneau, M.; Hoffmann, N. “The Paternò-Büchi Reaction - Mechanisms and Application to Organic Synthesis." J. Photochem. Photobiol. C Photochem. Rev. 2017, 33, 83-108. b) D'Auria, M. “The Paternò-Büchi Reaction - A Comprehensive Review." Photochem. Photobiol. Sci. 2019, 18, 2297-2362.

$6 \mathrm{Hu}$, S.; Neckers, D. C. "Rapid Regio- and Diastereoselective Paternò-Büchi Reaction of Alkyl Phenylglyoxylates." J. Org. Chem. 1997, 62, 564-567.

${ }^{7}$ Herkstroeter, W. G.; Lamola, A. A.; Hammond, G. S. "Mechanisms of Photochemical Reactions in Solution. XXVIII. 1 Values of Triplet Excitation Energies of Selected Sensitizers." J. Am. Chem. Soc. 1964, 86, 4537-4540.
Madison are funded by the NIH (1S10 OD020022-1) and a generous gift from the Paul J. and Margaret M. Bender Fund.

\section{REFERENCES}

${ }^{8}$ Lowry, M. S.; Goldsmith, J. I.; Slinker, J. D.; Rohl, R.; Pascal, R. A., Jr.; Malliaras, G. G.; Bernhard, S. "Single-layer electroluminescent devices and photoinduced hydrogen production from an ionic iridium(III) complex." Chem. Mater. 2005, 17, 5712-5719.

${ }^{9}$ Yoon, T. P. "Photochemical Stereocontrol Using Tandem PhotoredoxChiral Lewis Acid Catalysis.” Acc. Chem. Res. 2016, 49, 2307-2315.

${ }^{10}$ a) Russell, G. A.; Strom, E. T.; Talaty, E. R.; Weiner, S. A. "Semidiones. I. Acyclic Semidione Radical Anions and Cations Containing a Single Aryl Substituent." J. Am. Chem. Soc. 1966, 88, 1998-2004. b) Spaccini, R.; Pastori, N.; Clerici, A.; Punta, C.; Porta, O. "Key Role of Ti(IV) in the Selective Radical-Radical Cross-Coupling Mediated by the Ingold-Fischer Effect.” J. Am. Chem. Soc. 2008, 130, 18018-18024.

${ }^{11}$ Reckenthäler, M.; Neudörfl, J.-M.; Zorlu, E.; Griesbeck, A. G. “Combined Photoredox and Lewis Acid Catalyzed $\alpha$-Hydroxyalkylation of Cyclic Ethers with Aromatic Ketones.” J. Org. Chem. 2016, 81, 7211-7216.

12 a) Yang, N. C.; Yang, D.-D. H. "Photochemical Reactions of Ketones in Solution.” J. Am. Chem. Soc. 1958, 80, 2913-2914. b) Chen, C. "The Past, Present, and Future of the Yang Reaction.” Org. Biomol. Chem. 2016, 14, 8641-8647.

${ }^{13} \mathrm{Hu}, \mathrm{S}$.; Neckers, D. C. "Photocycloaddition and ortho-Hydrogen Abstraction Reactions of Methyl Arylglyoxylates: Structure Dependent Reactivities." J. Chem. Soc. Perkin Trans. 2 1999, 1771-1778.

14 a) Peglion, J.-L.; Vian, J.; Vilaine, J.-P.; Villeneuve, N.; Janiak, P.; Bidouard, J.-P. “3-Benzazépin-zones substituées par un groupe benzocyclobutyl- ou indanyl-alkyl-amino-alkyle, utiles dans le traitement des affections cardiovasculaires,” European Patent Office EP0534859A1, March 31, 1993. b) Hu, X.-R.; Chou, G.-X.; Zhang, C.-G. "Flavonoids, Alkaloids from the Seeds of Crotalaria Pallida and Their Cytotoxicity and Anti-Inflammatory Activities.” Phytochemistry 2017, 143, 64-71. c) Hu, X.-R.; Chou, G.-X.; Zhang, C.-G. "Flavonoids, Alkaloids from the Seeds of Crotalaria Pallida and Their Cytotoxicity and Anti-Inflammatory Activities.” Phytochemistry 2017, 143, 64-71. d) Hu, X.-R.; Chou, G.-X.; Zhang, C.-G. "Flavonoids, Alkaloids from the Seeds of Crotalaria Pallida and Their Cytotoxicity and Anti-Inflammatory Activities." Phytochemistry 2017, 143, 64-71.

${ }^{15}$ Roth, H. G.; Romero, N. A.; Nicewicz, D. A. "Experimental and Calculated Electrochemical Potentials of Common Organic Molecules for Applications to Single-Electron Redox Chemistry." Synlett 2016, 27, 714-723.

${ }^{16}$ Mizuno, K.; Ikeda, M.; Otsuji, Y. "Dual Regioselectivity in the Photoallylation of Electron-Deficient Alkenes by Allylic Silanes.” Chem. Lett. 1988, $17,1507-1510$ 